\title{
Click synthesis and adhesive properties of novel biomass-based polymers from lignin-derived stable metabolic intermediate
}

\author{
Tsuyoshi Michinobu ${ }^{1,2}$, Kenta Hiraki ${ }^{1}$, Yasunori Inazawa ${ }^{1}$, Yoshihiro Katayama ${ }^{3,6}$, Eiji Masai ${ }^{4}$, \\ Masaya Nakamura ${ }^{5}$, Seiji Ohara ${ }^{5}$ and Kiyotaka Shigehara ${ }^{1}$
}

Novel biomass-based polymers composed of 2-pyrone-4,6-dicarboxylic acid (PDC), which was isolated from lignin as a chemically stable metabolic intermediate, were synthesized by the copper (Cu) (I)-catalyzed, but ligand-free azide-alkyne cycloaddition reaction. The polymerization progress was monitored by the gel permeation chromatography profiles and IR spectroscopies. Very high-molecular-weight polymers with sufficient solubilities in organic solvents were obtained after the polymerization for $70 \mathrm{~h}$, and their chemical structures were fully characterized. The in-situ prepared PDC polymers displayed adhesive properties to various metal surfaces. Among the investigated metals, the tensile strength with $\mathrm{Cu}$, prepared at $70^{\circ} \mathrm{C}$ for $4 \mathrm{~h}$, was the highest (3.70 MPa). This specific adhesion to $\mathrm{Cu}$ is probably due to the promoted polymerization using the leached $\mathrm{Cu}^{\mathrm{l}}$ as a catalyst and the crosslinking ability through the interactions with the formed triazole rings.

Polymer Journal (2011) 43, 648-653; doi:10.1038/pj.2011.40; published online 11 May 2011

Keywords: adhesive; biomass; click chemistry; polyaddition

\section{INTRODUCTION}

Biomass-based renewable materials have attracted considerable attention as a source of green plastics. ${ }^{1-5}$ Lignin is a waste biomass that has three-dimensional network structures containing aromatic rings, and its conversion into versatile soluble monomers has been requested. In a previous study, we succeeded in the metabolic conversion of lignin into 2-pyrone-4,6-dicarboxylic acid (PDC) on a large scale via protocatechuate by a transformed bacterium. ${ }^{6}$ PDC consists of a polar pseudo-aromatic ring and two carboxylic acids, suggesting the potential use as a bifunctional monomer for polycondensation and polyaddition. As PDC was not accessible from petrochemicals, its chemical reactivity and physical properties were comprehensively investigated. ${ }^{7-9}$ During the course of the synthetic studies of PDC polymers, it was found that PDC is unstable under basic conditions. Thus, all the PDC polymers reported so far were synthesized by base-free reactions. In the past few years, a series of PDC polyesters was synthesized by the direct dehydrated polycondensation with various diol co-monomers, and their excellent biodegradable, mechanical and adhesive properties were demonstrated. ${ }^{10-16}$ However, the major problem of the PDC polyesters was their relatively low molecular weights. In order to improve the polymer properties, other efficient base-free polymerization methods were desired.
A $\mathrm{Cu}^{\mathrm{I}}$-catalyzed azide-alkyne cycloaddition (CuAAC), known as a representative click chemistry reaction, became an important polymerization method for achieving high-molecular-weight polymers. ${ }^{17-22}$ Owing to the chemical orthogonality, a wide variety of functional substances was polymerized under mild conditions. Although the reaction usually requires basic amines as a ligand of the $\mathrm{Cu}$ catalysts, there are also some reports of a ligand-free CuAAC. ${ }^{23,24}$ In addition, the powerful metal-adhesive features of the poly(triazole) products were previously demonstrated. ${ }^{25-27}$ As the biomass-based PDC polymers essentially show strong adhesive properties, it is reasonable to pursue the novel PDC polymers by the ligand-free CuAAC. In other words, the purpose of this work is to investigate the adhesive properties of the PDC polymers prepared by the ligand-free CuAAC. In this paper, we report for the first time the click polymerization of a PDC monomer, which was analyzed by ${ }^{1} \mathrm{H}$ NMR and IR spectroscopies, as well as its gel permeation chromatography (GPC) profiles. (For a preliminary communication of this work, see Michinobu et al. ${ }^{28}$ ) The adhesive properties of the in-situ prepared PDC polymers with various metal surfaces are also reported.

\section{EXPERIMENTAL PROCEDURE}

Materials

Chemicals and dehydrated solvents were purchased from Kanto (Tokyo, Japan), Tokyo Kasei (Tokyo, Japan) and Wako (Osaka, Japan), and used as received.

\footnotetext{
${ }^{1}$ Graduate School of Engineering and Institute of Symbiotic Science and Technology, Tokyo University of Agriculture and Technology, Tokyo, Japan; ${ }^{2}$ Global Edge Institute, Tokyo Institute of Technology, Tokyo, Japan; ${ }^{3}$ Graduate School of Bio-Applications and Systems Engineering, Tokyo University of Agriculture and Technology, Tokyo, Japan; ${ }^{4}$ Department of Bioengineering, Nagaoka University of Technology, Niigata, Japan and ${ }^{5}$ Forestry and Forest Products Research Institute, Tsukuba, Japan ${ }^{6}$ Current address: College of Bioresource Science, Nihon University, Fujisawa, Kanagawa 252-0880, Japan.

Correspondence: Dr T Michinobu or Professor K Shigehara, Graduate School of Engineering and Institute of Symbiotic Science and Technology, Tokyo University of Agriculture and Technology, Koganei, 184-8588 Tokyo, Japan.

E-mail: michinobu.t.aa@m.titech.ac.jp or jun@cc.tuat.ac.jp
}

Received 19 January 2011; revised 24 March 2011; accepted 31 March 2011; published online 11 May 2011 
1,2-Bis(2-azidoethoxy)ethane, ${ }^{29}$ and 2,2-bis(azidomethyl)propane-1,3-diol, ${ }^{30}$ diprop-2-ynyl isophthalate $2^{31}$ were prepared according to the literature method.

\section{Measurements}

${ }^{1} \mathrm{H}$ NMR and ${ }^{13} \mathrm{C}$ NMR spectra were measured on a JEOL (Tokyo, Japan) model AL300 spectrometer at $20^{\circ} \mathrm{C}$. Chemical shifts are reported in p.p.m. downfield from $\mathrm{SiMe}_{4}$, using the solvent's residual signal as an internal reference. The resonance multiplicity is described as s (singlet), br s (broad singlet), d (doublet) and $\mathrm{m}$ (multiplet). Infrared spectra were recorded on a JASCO (Tokyo, Japan) FT/IR-4100 spectrometer. Gel permeation chromatography was measured on a JASCO system equipped with a HITACHI L-4000 UV detector $(275 \mathrm{~nm})$, a Spectra-Physics SP8800 ternary HPLC pump, and polystyrene gel columns (Shodex Asahipak GF-310 HQ, GF-410 HQ, and GF-710 HQ with the exclusion limit molecular weight of 40000, 300000 and 10000000 , respectively) using dimethylformamide (DMF) as an eluent at a flow rate of $0.5 \mathrm{ml} \mathrm{min}^{-1}$ after calibration with standard polystyrenes (TOSOH (Tokyo, Japan) TSK standard polystyrene). Thermogravimetric analyses were carried out on a Rigaku (Tokyo, Japan) Thermo plus TG8120 under nitrogen flow at the heating rate of $10^{\circ} \mathrm{C} \mathrm{min}^{-1}$ from 20 to $500^{\circ} \mathrm{C}$. X-ray photoelectron spectroscopy measurement was performed using a JASCO JPS-9010TR.

Tensile strength measurements were performed according to JIS K 68491994 testing method. The size and length of metal plate edges (brass, $\mathrm{Fe}, \mathrm{Cu}$ ) for adhesion measurements were $5.0 \times 28.0 \mathrm{~mm}^{2}$ and $50 \mathrm{~mm}$, respectively. The edge plane surfaces were smoothened by a rotating disk diamond cutter or a horizontal milling machine, followed by polishing with diamond sands/oil or alumina powders/oil combinations. The surface coarseness of $<0.6 \mu \mathrm{m}$ was confirmed by surface profilometry using a Toyo Technica (Tokyo, Japan) Dek-Tak IIA. Then, the plates were washed under sonication with a series of solvents, such as 1,2-dichloroethane, methanol and water. A solution of $1 / 2$ and 2,2-bis(azidomethyl)propane-1,3-diol was cast on the metal plate surfaces. A set of two plates was in contact with each other and cured at $70^{\circ} \mathrm{C}$ for $4 \mathrm{~h}$ or at $100^{\circ} \mathrm{C}$ for $1 \mathrm{~h}$. The adhesion strengths of the cured films were measured at $21 \pm 2{ }^{\circ} \mathrm{C}$ under dry nitrogen using a Tensilon testing machine (Auto COM/AC-50A, TS Engineering (Kenosha, WI, USA)).

\section{Synthesis}

Diprop-2-ynyl 2-oxo-2H-pyran-4,6-dicarboxylate (1). To a solution of propargyl alcohol $(0.706 \mathrm{ml}, 12.0 \mathrm{mmol})$ and $N, N$-dimethylaminopyridine $(133 \mathrm{mg}$, $1.09 \mathrm{mmol})$ in 1,2-dimethoxyethane $(100 \mathrm{ml})$, PDC $(1.00 \mathrm{~g}, 5.43 \mathrm{mmol})$ was added under nitrogen. After cooling to $0^{\circ} \mathrm{C}$, dicyclohexylcarbodiimide $(2.69 \mathrm{~g}$, $13.0 \mathrm{mmol}$ ) was added, and then warmed to $20^{\circ} \mathrm{C}$ and stirred for $5 \mathrm{~h}$. The precipitates were filtered off and the filtrate was washed with water and dried over $\mathrm{Na}_{2} \mathrm{SO}_{4}$. Evaporation of the solvents and column chromatography $\left(\mathrm{SiO}_{2}\right.$, acetone/hexane 1:1) afforded $1(1.02 \mathrm{~g}, 72 \%)$ as a white solid.

${ }^{1} \mathrm{H}$ NMR $\left(300 \mathrm{MHz}, \mathrm{DMSO}_{-}, \mathrm{d}_{6}, 293 \mathrm{~K}\right) \delta 3.72(\mathrm{~s}, 2 \mathrm{H}), 4.99-5.01(\mathrm{~m}, 4 \mathrm{H})$, $7.14(\mathrm{~d}, J=3 \mathrm{~Hz}, 1 \mathrm{H}), 7.28$ p.p.m. $(\mathrm{d}, J=3 \mathrm{~Hz}, 1 \mathrm{H}) ;{ }^{13} \mathrm{C}$ NMR $(75 \mathrm{MHz}$, DMSO-d $\left._{6}, 293 \mathrm{~K}\right) \delta 53.90,54.09,77.40,78.94,108.24,122.82,141.94,148.12$, 157.91, 159.24, 161.61 p.p.m.; IR (neat): $v$ 3272, 3087, 2122, 1752, 1733, 1716, $1559,1440,1418,1378,1340,1275,1249,1178,1129,1092,1019,981,962,931$, $891,778,763,721,690,668 \mathrm{~cm}^{-1}$.
(P1). To a solution of 1,2-bis(2-azidoethoxy)ethane ( $387 \mathrm{mg}, 1.92 \mathrm{mmol}$ ) and copper(I) bromide (50 mol\%, $276 \mathrm{mg}, 1.92 \mathrm{mmol})$ in dehydrated DMF $(10 \mathrm{ml})$, $1(500 \mathrm{mg}, 1.92 \mathrm{mmol})$ was added at $20^{\circ} \mathrm{C}$. After stirring for $70 \mathrm{~h}$, the reaction mixture was filtered off and the filtrate was evaporated to be approximately 2-3 ml. Precipitation into $\mathrm{CH}_{3} \mathrm{OH}(300 \mathrm{ml})$ afforded the target polymer P1, which was filtered off, thoroughly washed with $\mathrm{CH}_{3} \mathrm{OH}$ and then dried in vacuo (621 mg, 70\%).

${ }^{1} \mathrm{H}$ NMR $\left(300 \mathrm{MHz}, \mathrm{DMSO}_{6}, \mathrm{~d}_{6}, 293 \mathrm{~K}\right) \delta 3.74(\mathrm{~s}, 4 \mathrm{n} \mathrm{H}), 4.48($ br s, $8 \mathrm{n} \mathrm{H})$, 5.38 (br s, 4n H), 7.03 (br s, n H), 7.17 (br s, n H), 8.20 p.p.m. (br s, 2n H); IR (neat): $v 2924,2876,1734,1642,1559,1436,1395,1351,1314,1253,1124,959$, $826,761,710 \mathrm{~cm}^{-1}$.

(P2). To a solution of 2,2-bis(azidomethyl)propane-1,3-diol (180 mg, $0.967 \mathrm{mmol})$ and copper(I) iodide $(13 \mathrm{mg}, 0.068 \mathrm{mmol})$ in dehydrated DMF $(3 \mathrm{ml}), 1(252 \mathrm{mg}, 0.967 \mathrm{mmol})$ was added at $20^{\circ} \mathrm{C}$. After stirring for $43 \mathrm{~h}$, the reaction mixture was filtered off and the filtrate was evaporated to be approximately $2-3 \mathrm{ml}$. Precipitation into $\mathrm{CH}_{3} \mathrm{CN}(60 \mathrm{ml})$ afforded the target polymer $\mathbf{P} 2$, which was filtered off, thoroughly washed with acetone, THF and $\mathrm{CHCl}_{3}$ and then dried in vacuo $(314 \mathrm{mg}, 73 \%$ ).

${ }^{1} \mathrm{H}$ NMR $\left(300 \mathrm{MHz}\right.$, DMSO-d $\left.\mathrm{d}_{6}, 293 \mathrm{~K}\right) \delta 3.08-3.40(\mathrm{~m}, 8 \mathrm{n} \mathrm{H}), 4.21-4.38$ (m, 2n H), 5.01-5.40 (m, 4n H), 6.97-7.23 (m, 2n H), 8.19 p.p.m. (s, 2n H); IR (neat): $v$ 3420, 2934, 2883, 2108 (w), 1736, 1654, 1560, 1440, 1390, 1328, 1247, $1171,1115,1050,959,876,761,665 \mathrm{~cm}^{-1}$.

\section{RESULTS AND DISCUSSION}

\section{Polymer synthesis and characterization}

The transformation of the carboxylic-acid moieties of PDC into either terminal alkynes or azide functions was attempted. It was found that the common condensing agents, such as dicyclohexylcarbodiimide and $N, N$-dimethylaminopyridine, were effective for the esterification of the carboxylic-acid moieties of PDC. Thus, 2 equivalent of propargyl alcohol was reacted with PDC, providing 1 in $72 \%$ yield (Scheme 1). The dipropargyl PDC 1 was stable in neutral $\mathrm{pH}$, but the ethynyl moieties and the pyrone ring were unstable in the acidic and basic $\mathrm{pH}$ regions, respectively. We also tried to prepare a diazidefunctionalized PDC monomer as a complementary monomer for the click polymerization with $\mathbf{1}$. However, the esterification of the PDC carboxylates with 2-bromoethanol followed by the reaction with sodium azide gave an unidentified product, probably due to the intramolecular side reaction between the pyrone ring and azide moieties.

The click polymerization of 1 was carried out at $20^{\circ} \mathrm{C}$ in DMF with an equimolar amount of the diazide co-monomers, 1,2-bis(2-azidoethoxy)ethane or 2,2-bis(azidomethyl)propane-1,3-diol, in the presence of the $\mathrm{Cu}^{\mathrm{I}}$ catalyst. It is generally known that the conventional click polymerization using CuAAC proceeds very smoothly. In contrast, a partial polymerization progress could be monitored by the GPC profiles in this study, because the reaction rate became slower because of the absence of basic amino ligands. As shown in Figure 1,

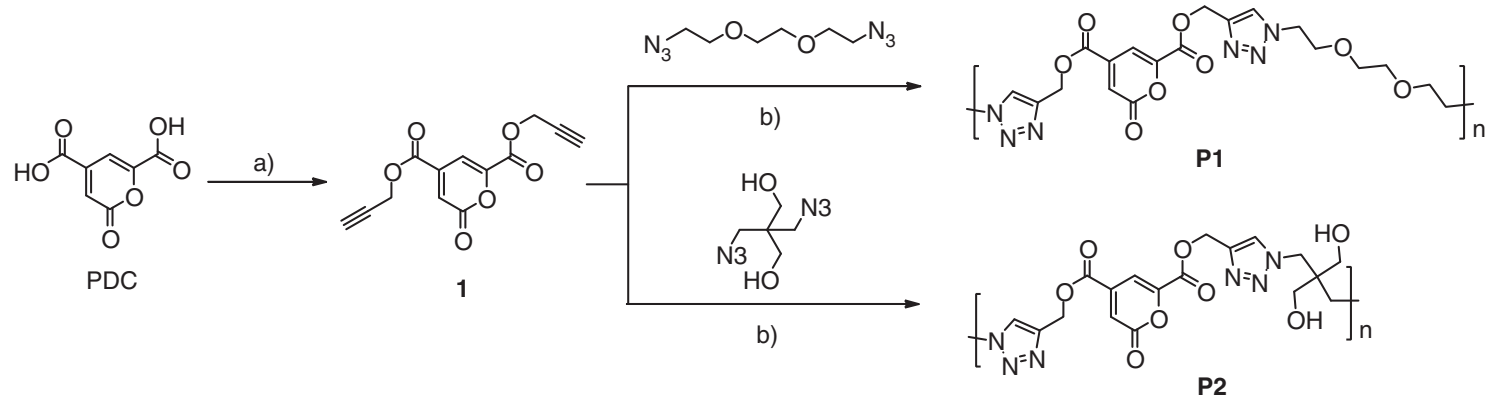

Scheme 1 Click polymerization of dipropargyl-PDC. (a) Propargyl alcohol, dicyclohexylcarbodiimide, $N, N$-dimethylaminopyridine (DMAP), $0-20{ }^{\circ} \mathrm{C}, 72 \%$; (b) $\mathrm{CuBr}$, dimethylformamide (DMF), $20^{\circ} \mathrm{C}$. 


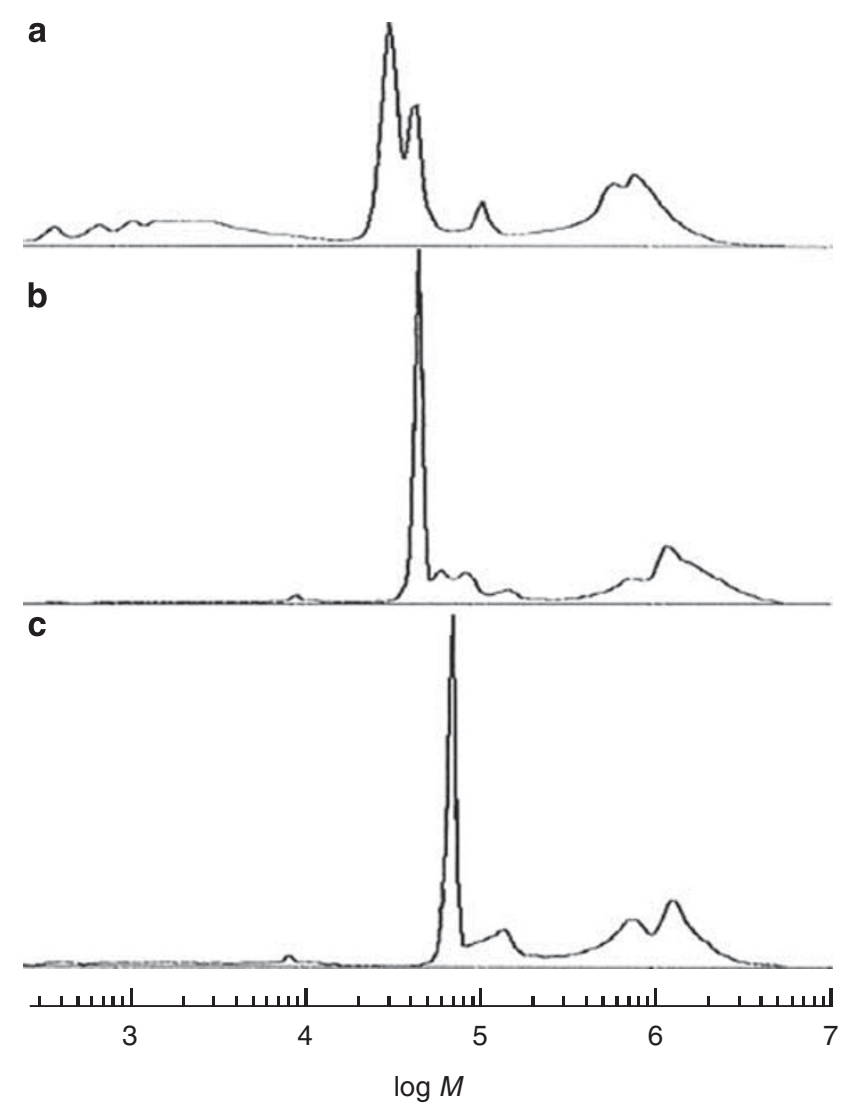

Figure 1 Gel permeation chromatography (GPC) profiles (eluent: dimethylformamide (DMF)) of $\mathbf{P 1}$ for the polymerization time of (a) 15, (b) 27 and (c) $70 \mathrm{~h}$.

there were mainly three fractions after the polymerization for $15 \mathrm{~h}$, that is, a small-molecular-weight fraction with the molecular weight of $<10^{4}$, a moderate-molecular-weight fraction with very sharp peaks at approximately $10^{5}$, and a very large-molecular-weight fraction with the molecular weight of approximately $10^{6}$. The presence of the largemolecular-weight fraction suggested that the polymerization rate was basically fast. When the polymerization time was prolonged to $27 \mathrm{~h}$, the small-molecular-weight fractions almost disappeared, whereas the moderate-molecular-weight fractions still existed. The polymerization time was further prolonged to $70 \mathrm{~h}$, resulting in the saturation of the molecular weight increase in the large-molecular-weight fractions. This saturation was most likely caused by a significant increase in the solution viscosity or deposition from the polymerization solution. Therefore, the polymerization was terminated and the products were purified by completely washing with methanol.

The polymerization was also monitored by the IR spectra of the powder samples. In the IR spectrum of the $15-\mathrm{h}$ polymerization product, the azide peak at $2109 \mathrm{~cm}^{-1}$ still remained, whereas the peaks at 3272 and $2122 \mathrm{~cm}^{-1}$, ascribed to the $\mathrm{C}-\mathrm{H}$ and $\mathrm{C} \equiv \mathrm{C}$ vibrations of the terminal alkyne moieties, respectively, were almost negligible (Figure 2). In accordance with the GPC profiles, when the polymerization time was prolonged, the azide peak completely disappeared, indicating the efficient conversion into very large-molecular-weight products.

On the basis of these results, the high-molecular-weight polymers P1 and P2 were prepared at $20^{\circ} \mathrm{C}$ under base-free conditions. The molecular weights of the resulting linear polymers, determined

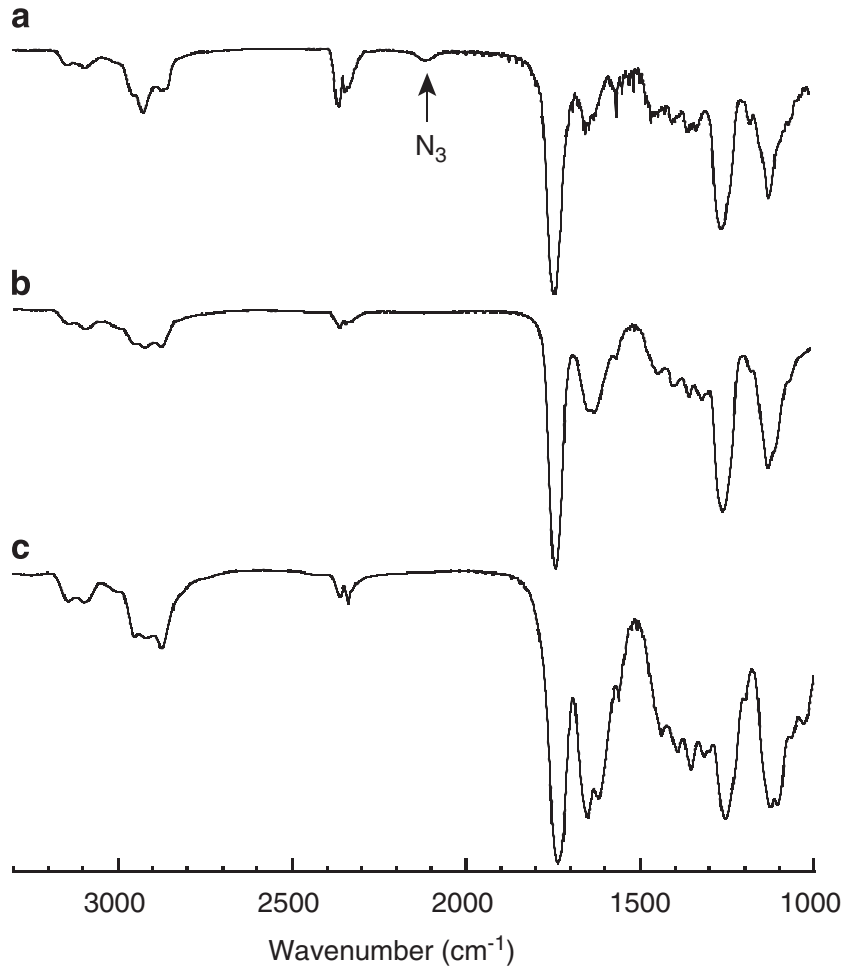

Figure 2 Infra red spectra ( $\mathrm{KBr}$ pellet) of $\mathbf{P} \mathbf{1}$ for the polymerization time of (a) 15, (b) 27 and (c) $70 \mathrm{~h}$.

by GPC using DMF as an eluent, exceeded 1000000 (Table 1). Longer polymerization time tended to produce the higher-molecular-weight polymers, whereas an increase in the catalyst amount from 7 to $50 \mathrm{~mol} \%$ did not improve the molecular weights, suggesting that a catalytic amount of $\mathrm{Cu}^{\mathrm{I}}$ was sufficient to achieve high-molecularweight polymers. The problem with increasing the $\mathrm{Cu}^{\mathrm{I}}$ amount was the difficulty in perfectly removing the $\mathrm{Cu}$ ions because of the presumed interaction of $\mathrm{Cu}^{\mathrm{II}}$ with the formed triazole products. ${ }^{32}$ The residual $\mathrm{Cu}$ was indeed detected when the $\mathrm{X}$-ray photoelectron spectroscopy measurement of $\mathbf{P 1}$, prepared in the presence of $50 \mathrm{~mol} \% \mathrm{Cu}^{\mathrm{I}}$, was performed (Supplementary Figure S1). Although these remaining $\mathrm{Cu}$ ions were thought to interact with the triazole moieties, they did not significantly affect the GPC profiles. In contrast, the chemical structure of the di-azide co-monomers affected the polymerization results. Taking into account the molecular weights of the high-molecular-weight fractions obtained under the same conditions ( $7 \mathrm{~mol} \%$ of $\mathrm{Cu}^{\mathrm{I}}$ catalyst, $20^{\circ} \mathrm{C}, 43 \mathrm{~h}$ ), 1,2-bis(2-azidoethoxy) ethane was a better co-monomer compared with 2,2,-bis(azidomethyl)propane-1,3-diol. Despite the high molecular weight exceeding 1000000 , these polymers were soluble in DMF and DMSO. In addition, P1 was sparsely soluble in THF. Thus, the ${ }^{1} \mathrm{H}$ NMR spectra of $\mathbf{P} 1$ and $\mathbf{P} 2$ were measured in DMSO- $\mathrm{d}_{6}$ at $20^{\circ} \mathrm{C}$. The PDC protons and triazole proton were detected in the desired aromatic region (Figure 3). Owing to the asymmetric chemical structure of PDC, multiple peaks were observed for some of these protons. The aliphatic protons were also clearly detected, suggesting the occurrence of the copolymerization.

\section{Thermal properties}

The thermal properties of the PDC polymers were investigated by a thermogravimetric analysis at the heating rate of $10^{\circ} \mathrm{C} \mathrm{min}^{-1}$ under 
a nitrogen atmosphere. Although most of the reported PDC polyesters showed a single-step decomposition with the onset decomposition temperature of $>200{ }^{\circ} \mathrm{C},{ }^{10-13}$ the decomposition of P1 and P2 proceeded in two or three steps with the onset decomposition temperature of 190 and $160^{\circ} \mathrm{C}$, respectively, (Figure 4). The decreased thermal stabilities of $\mathbf{P} \mathbf{1}$ and $\mathbf{P} \mathbf{2}$ were probably due to the co-monomer structures. However, the residual soot amounts of $\mathbf{P} 1$ and $\mathbf{P} 2$ at $500{ }^{\circ} \mathrm{C}$ were 55 and $35 \%$, respectively, which were much greater than the previous PDC polyesters. Thus, it is suggested that an increase in the nitrogen content most likely leads to a higher soot amount from the thermal decomposition process. Note that the possibility of the residual $\mathrm{Cu}$ contamination was not ruled out. Differential scanning calorimetry measurements of $\mathbf{P 1}$ and $\mathbf{P} 2$ did not show any transitions in the temperature range from -50 to $150{ }^{\circ} \mathrm{C}$.

Table 1 Polymerization results of dipropargyl-PDC ${ }^{a}$

\begin{tabular}{lcrc}
\hline Polymer & $M_{w}$ & $M_{n}$ & $M_{w} / M_{n}$ \\
\hline P1 $^{\mathrm{b}}$ & 4345000 & 1519000 & 2.86 \\
P1 $^{\mathrm{c}}$ & 7524000 & 1480000 & 5.08 \\
P2 $^{\mathrm{c}}$ & 1272000 & 330000 & 3.85
\end{tabular}

Abbreviation: PDC, 2-pyrone-4,6-dicarboxylic acid.

aHigh-molecular-weight fractions.

brepared in the presence of $\mathrm{Cu}^{\prime}$ catalyst $(50 \mathrm{~mol} \%)$ at $20^{\circ} \mathrm{C}$ for $168 \mathrm{~h}$.

cPrepared in the presence of $\mathrm{Cu}^{\prime}$ catalyst $(7 \mathrm{~mol} \%)$ at $20^{\circ} \mathrm{C}$ for $43 \mathrm{~h}$.

\section{Adhesive properties}

It was reported that the PDC polyesters show strong adhesive properties toward metal and glass surfaces. ${ }^{11,15}$ In addition, the first noticeable application of CuAAC in materials science was the specific adhesion of poly(triazole) derivatives to a $\mathrm{Cu}$ surface, which was achieved by the partial crosslinking of the polymer chains with a small amount of the leached $\mathrm{Cu}^{\mathrm{I}}{ }^{25}$

As $\mathbf{P 1}$ and P2 contain both PDC and triazole moieties, they are promising materials for adhesive applications. We focused on the

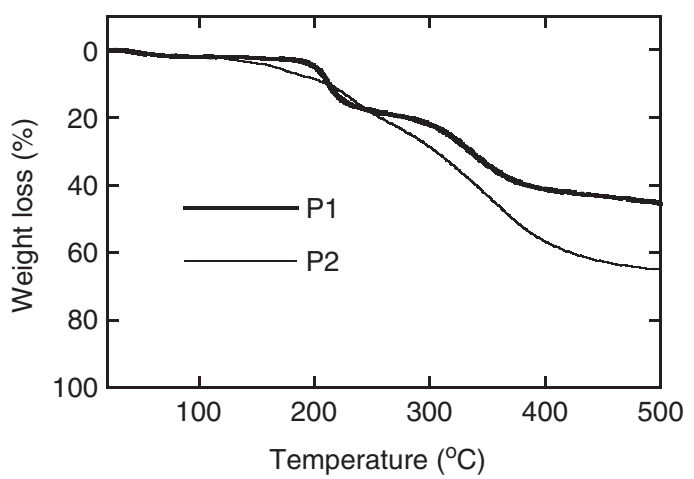

Figure 4 Thermogravimetric analyses curves of $\mathbf{P} \mathbf{1}$ and $\mathbf{P} \mathbf{2}$ at the heating rate of $10^{\circ} \mathrm{C} \mathrm{min}^{-1}$ under flowing nitrogen.
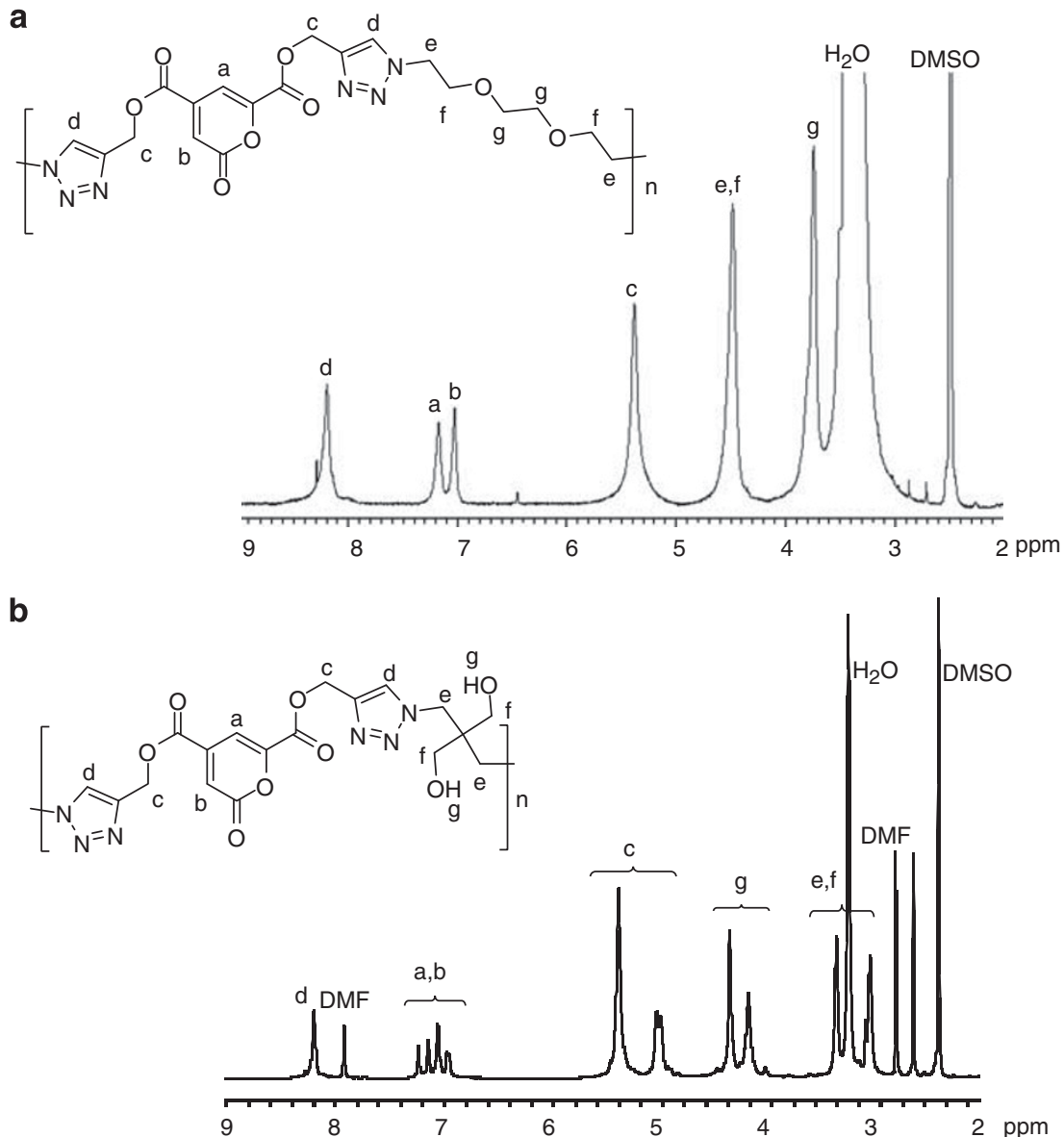

Figure $3{ }^{1} \mathrm{H}$ NMR spectra of (a) P1 and (b) P2 in DMSO-d 6 at $20^{\circ} \mathrm{C}$. 
adhesive properties of $\mathbf{P} 2$ to various metal surfaces, because the PDC and triazole contents of $\mathbf{P 2}$ are greater than those of $\mathbf{P 1}$. After a solution of an equimolar amount of $\mathbf{1}$ and 2,2-bis(azidomethyl)propane-1,3-diol was cast on the metal surface, they were in-situ polymerized at $70^{\circ} \mathrm{C}$ for $4 \mathrm{~h}$ or at $100^{\circ} \mathrm{C}$ for $1 \mathrm{~h}$. The polymerization conditions were determined so that no thermal decomposition occurred. When $\mathrm{Cu}$ was used as a metal, a small amount of the leached $\mathrm{Cu}^{\mathrm{I}}$ was expected to serve as a catalyst to promote the polymerization and regioregularity control. Note that the products are basically a mixture of 1,4-triazole and 1,5-triazole derivatives on other metal surfaces. ${ }^{24}$ Tensile strength measurements were performed against brass, $\mathrm{Fe}$ and $\mathrm{Cu}$ plates, according to the JIS K 6849-1994 testing method. For all the three metal plates, $\mathbf{P} 2$ prepared at $70{ }^{\circ} \mathrm{C}$ for $4 \mathrm{~h}$ showed higher tensile strengths than that prepared at $100^{\circ} \mathrm{C}$ for $1 \mathrm{~h}$ (Figure 5 and Table 2). In addition, a slightly better elongation occurred under the former conditions. Among the three metals, P2 displayed the strongest adhesion to $\mathrm{Cu}$, probably due to the catalytic effect and/or the crosslinking through the multivalent coordination to the triazole rings. Thus, the maximum tensile strengths to brass, $\mathrm{Fe}$ and $\mathrm{Cu}$ plates were $2.89,3.16$ and $3.70 \mathrm{MPa}$, respectively. The previously reported PDC polyesters displayed a stronger adhesion to brass and Fe plates than to $\mathrm{Cu}$ plates. ${ }^{11}$ This interesting inversion is

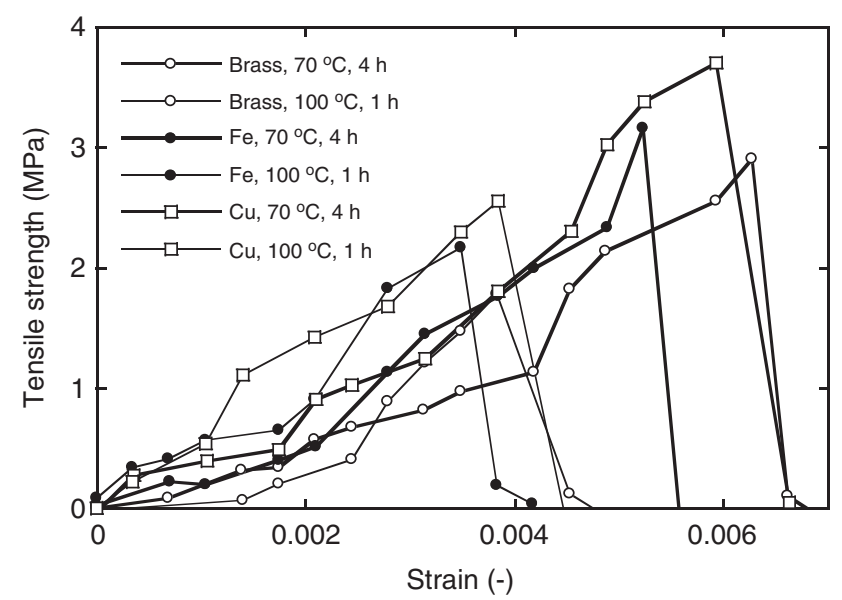

Figure 5 Adhesion properties of the in-situ prepared $\mathbf{P} \mathbf{2}$ with brass, Fe and copper (Cu) under different conditions (at $70^{\circ} \mathrm{C}$ for $4 \mathrm{~h}$ or at $100^{\circ} \mathrm{C}$ for $1 \mathrm{~h}$ ).

Table 2 Adhesion conditions and tensile strength (MPa) of P2 by JIS K 6849-1994 testing

\begin{tabular}{lcc}
\hline & $70^{\circ} \mathrm{C}, 4 \mathrm{~h}$ & $100^{\circ} \mathrm{C}, 1 \mathrm{~h}$ \\
\hline Brass & 2.89 & 1.59 \\
$\mathrm{Fe}$ & 3.16 & 2.17 \\
$\mathrm{Cu}$ & 3.70 & 2.56 \\
\hline
\end{tabular}

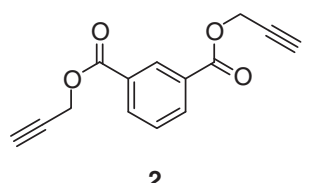

Scheme 2 Chemical structure of 2. apparently caused by the introduction of the click-formed triazole rings. Moreover, the effect of the PDC ring was also elucidated using diprop-2-ynyl isophthalate 2 , in place of $\mathbf{1}$ (Scheme 2). The tensile strength measurements of the cured films prepared from 2 and 2,2-bis(azidomethyl)propane-1,3-diol were attempted. However, these films were too fragile to be measured, although numerous combinations of curing conditions and various metals were tested. These results clearly suggested the important role of the pyrone ring to generate the specific adhesion. A plausible adhesion mechanism is based on the carbonyl group coordination to the metal atoms, accompanying the pyrone ring opening. ${ }^{11}$

\section{CONCLUSION}

Very high-molecular-weight PDC polymers with well-defined chemical structures were for the first time synthesized by the ligand-free CuAAC. As the PDC polymers were soluble in DMF and DMSO and sparsely soluble in THF, they were fully characterized. Investigations of the adhesive properties to various metals revealed that the pyrone ring is essential for better adhesion, and the triazole rings show specific interactions to $\mathrm{Cu}$. Thus, the maximum tensile strength to $\mathrm{Cu}$ plates was $3.70 \mathrm{MPa}$. Further optimization of the chemical structures, for example, multi-functionalized monomers for efficient crosslinking, is expected to improve the adhesive properties.

\section{ACKNOWLEDGEMENTS}

This work was supported, in part, by a Grant-in-Aid for Scientific Research and Special Coordination Funds for Promoting Science and Technology from MEXT, Japan. We thank Dr K Mase and Dr T Abe (Tokyo University of Agriculture and Technology) for the GPC measurements. Y Washino (Tokyo Institute of Techology) is acknowledged for help in the polymer synthesis.

1 Ragauskas, A. J., Williams, C. K., Davison, B. H., Britovsek, G., Cairney, J., Eckert, C. A., Frederick Jr, W. J., Hallett, J. P., Leak, D. J., Liotta, C. L., Mielenz, J. R., Murphy, R., Templer, R. \& Tschaplinski, T. The path forward for biofuels and biomaterials. Science 311, 484-489 (2006).

2 Matsumura, S. Enzymatic synthesis of polyesters via ring-opening polymerization. Adv. Polym. Sci. 194, 95-132 (2006).

3 Nishio, Y. Material functionalization of cellulose and related polysaccharides. Adv. Polym. Sci. 205, 97-151 (2006).

4 Williams, C. K. Synthesis of functionalized biodegradable polyesters. Chem. Soc. Rev. 36, 1573-1580 (2007).

5 Gandini, A. Polymers from renewable resources: a challenge for the future of macromolecular materials. Macromolecules 41, 9491-9504 (2008).

6 Otsuka, Y., Nakamura, M., Shigehara, K., Sugimura, K., Masai, E., Ohara, S. \& Katayama, Y. Efficient production of 2-pyrone 4,6-dicarboxylic acid as a novel polymer-based material from protocatechuate by microbial function. Appl. Microbiol. Biotechnol. 71, 608-614 (2006).

7 Michinobu, T., Bito, M., Yamada, Y., Katayama, Y., Noguchi, K., Masai, E., Nakamura, M., Ohara, S. \& Shigehara, K. Molecular properties of 2-pyrone-4,6-dicarboxylic acid (PDC) as a stable metabolic intermediate of lignin isolated by fractional precipitation with $\mathrm{Na}^{+}$ion. Bull. Chem. Soc. Jpn. 80, 2436-2442 (2007).

8 Bito, M., Michinobu, T., Katayama, Y., Otsuka, Y., Nakamura, M., Ohara, S., Masai, E. \& Shigehara, K. 2-Pyranone-4,6-dicarboxylic acid as a source of green-plastics and antibacterial chemicals. Trans. Mater. Res. Soc. Jpn. 33, 1165-1168 (2008).

9 Michinobu, T., Hiraki, K., Fujii, N., Shikinaka, K., Katayama, Y., Masai, E., Nakamura, M., Otsuka, Y., Ohara, S. \& Shigehara, K. Organogels of lignin-derived stable metabolic intermediate, 2-pyrone-4,6-dicarboxylic acid (PDC), bearing cholesteryl groups. Chem. Lett. 39, 400-401 (2010).

10 Michinobu, T., Hishida, M., Sato, M., Katayama, Y., Masai, E., Nakamura, M., Otsuka, Y., Ohara, S. \& Shigehara, K. Polyesters of 2-pyrone-4,6-dicarboxylic acid (PDC) obtained from a metabolic intermediate of lignin. Polym. J. 40, 68-75 (2008).

11 Hishida, M., Shikinaka, K., Katayama, Y., Kajita, S., Masai, E., Nakamura, M., Otsuka, Y., Ohara, S. \& Shigehara, K. Polyesters of 2-pyrone-4,6-dicarboxylic acid (PDC) as biobased plastics exhibiting strong adhering properties. Polym. J. 41, 297-302 (2009).

12 Michinobu, T., Bito, M., Tanimura, M., Katayama, Y., Masai, E., Nakamura, M., Otsuka, Y., Ohara, S. \& Shigehara, K. Mechanical properties of poly(L-lactide) films controlled by blending with polyesters of lignin-derived stable metabolic intermediate, 2-pyrone4,6-dicarboxylic acid (PDC). Polym. J. 41, 843-848 (2009). 
13 Michinobu, T., Bito, M., Yamada, Y., Tanimura, M., Katayama, Y., Masai, E., Nakamura, M., Otsuka, Y., Ohara, S. \& Shigehara, K. Fusible, elastic, and biodegradable polyesters of 2-pyrone-4,6-dicarboxylic acid (PDC). Polym. J. 41, 1111-1116 (2009).

14 Hishida, M., Shikinaka, K., Inazawa, Y., Katayama, Y., Kajita, S., Masai, E., Nakamura, M., Otsuka, Y., Ohara, S. \& Shigehara, K. [Conductive cements based polyesters of PDC (2-pyrone-4,6-dicarboxylic acid) obtained from a metabolic intermediate of lignin]. Kobunshi Ronbunshu 66, 141-146 (2009).

15 Hasegawa, Y., Shikinaka, K., Katayama, Y., Kajita, S., Masai, E., Nakamura, M., Otsuka, Y., Ohara, S. \& Shigehara, K. [Tenacious epoxy adhesives prepared from lignin-derived stable metabolic intermediate]. Sen'i Gakkaishi 65, 359-362 (2009).

16 Michinobu, T., Bito, M., Tanimura, M., Katayama, Y., Masai, E., Nakamura, M., Otsuka, Y., Ohara, S. \& Shigehara, K. Synthesis and characterization of hybrid biopolymers of L-lactic acid and 2-pyrone-4,6-dicarboxylic acid. J. Macromol. Sci, Part A; Pure Appl. Chem. 47, 564-570 (2010).

17 Kolb, H. C., Finn, M. G. \& Sharpless, K. B. Click chemistry: diverse chemical function from a few good reactions. Angew. Chem. Int. Ed. 40, 2004-2021 (2001)

18 Liu, J., Lam, J. W. Y. \& Tang, B. Z. Acetylenic polymers: syntheses, structures, and functions. Chem. Rev. 109, 5799-5867 (2009).

19 Qin, A., Lam, J. W. Y. \& Tang, B. Z. Click polymerization. Chem. Soc. Rev. 39, 2522-2544 (2010).

20 Qin, A., Lam, J. W. Y. \& Tang, B. Z. Click polymerization: progresses, challenges, and opportunities. Macromolecules 43, 8693-8702 (2010).

21 Nagao, Y. \& Takasu, A. Click polyester: synthesis of polyesters containing triazole units in the main chain by click chemistry and improved thermal property. Macromol. Rapid Commun. 30, 199-203 (2009).

22 Nagao, Y. \& Takasu, A. 'Click polyester': synthesis of polyesters containing triazole units in the main chain via safe and rapid 'click' chemistry and their properties. J. Polym. Sci., Part A: Polym. Chem. 48, 4207-4218 (2010).

23 Golas, P. L., Tsarevsky, N. V., Sumerlin, B. S. \& Matyjaszewski, K. Catalyst performance in 'click' coupling reactions of polymers prepared by ATRP: ligand and metal effects. Macromolecules 39, 6451-6457 (2006).
24 Qin, A., Jim, C. K. W., Lu, W., Lam, J. W. Y., Häussler, M., Dong, Y., Sung, H. H. Y., Williams, I. D., Wong, G. K. L. \& Tang, B. Z. Click polymerization: facile synthesis of functional poly(aroyltriazole)s by metal-free, regioselective 1,3-dipolar polycycloaddition. Macromolecules 40, 2308-2317 (2007).

25 Díaz, D. D., Punna, S., Holzer, P., Mcpherson, A. K., Sharpless, K. B., Fokin, V. V. \& Finn, M. G. Click chemistry in materials synthesis. 1. adhesive polymers from copper-catalyzed azide-alkyne cycloaddition. J. Polym. Sci., Part A: Polym. Chem. 42, 4392-4403 (2004).

26 Liu, Y., Díaz, D. D., Accurso, A. A., Sharpless, K. B., Fokin, V. V. \& Finn, M. G. Click chemistry in materials synthesis. III. metal-adhesive polymers from $\mathrm{Cu}(\mathrm{I})$-catalyzed azide-alkyne cycloaddition. J. Polym. Sci., Part A: Polym. Chem. 45, 5182-5189 (2007).

27 Tang, Y., Jim, C. K. W., Liu, Y., Ye, L., Qin, A., Lam, J. W. Y., Zhao, C. \& Tang, B. Z. Synthesis and curing of hyperbranched poly(triazole)s with click polymerization for improved adhesion strength. ACS Appl. Mater. Interfaces 2, 566-574 (2010).

28 Michinobu, T., Inazawa, Y., Hiraki, K., Katayama, Y., Masai, E., Nakamura, M., Ohara, S. \& Shigehara, K. A novel biomass-based polymer prepared from lignin-derived stable metabolic intermediate by copper(I)-catalyzed azide-alkyne click reaction. Chem. Lett. 37, 154-155 (2008).

29 Gatto, V. J., Arnold, K. A., Viscariello, A. M., Miller, S. R., Morgan, C. R. \& Gokel, G. W. Syntheses and binding properties of bibrachial lariat ethers (BiBLEs): survey of synthetic methods and cation selectivities. J. Org. Chem. 51, 5373-5384 (1986).

30 Besset, C., Bernard, J., Fleury, E., Pascault, J.- P., Cassagnau, P., Drockenmuller, E. \& Williams, R. J. J. Bio-sourced networks from thermal polyaddition of a starch-derived $\alpha$-azide- $\omega$-alkyne AB monomer with an A2B2 aliphatic cross-linker. Macromolecules 43, 5672-5678 (2010).

31 Lin, L., Shen, Q., Chen, G.- R. \& Xie, J. Synthesis of triazole-linked $\beta$-C-glycosyl dimers as inhibitors of PTB1B. Bioorg. Med. Chem. 16, 9757-9763 (2008).

32 Diaz, D. D., Marrero Tellado, J. J., Velazquez, D. G. \& Ravelo, A. G. Polymer thermoreversible gels from organogelators enabled by 'click' chemistry. Tetrahedron Lett. 49, 1340-1343 (2008).

Supplementary Information accompanies the paper on Polymer Journal website (http://www.nature.com/pj) 